\title{
Experimental Studies and Modeling of the Drying Kinetics of Multicomponent Polymer Films
}

\author{
Sitaram P. Velaga, ${ }^{1,2}$ Dariush Nikjoo, ${ }^{1}$ and Parameswara R. Vuddanda ${ }^{1}$
}

Received 22 May 2017; accepted 12 June 2017; published online 31 July 2017

\begin{abstract}
The process of drying thin polymer films is an important operation that influences the film structure and solid state, and the stability of the product. The purpose of this work was to study and model the drying kinetics of multicomponent films based on two polymers: hydroxypropyl methylcellulose (HPMC, amorphous) and polyvinyl alcohol (PVA, semicrystalline). The isothermal drying kinetics of the films at different temperatures $(40,60$, and $80^{\circ} \mathrm{C}$ ) were studied using thermo-gravimetric analysis (TGA) and convection oven methods. Solid-state characterization tools used in the study included polarization and hotstage microscopy, scanning electron microscopy (SEM), and differential scanning calorimetry (DSC). The drying kinetics of HPMC and PVA films in the TGA apparatus and convection oven were comparable. The three-parameter $\left(W_{\max }, \tau, n\right)$ Hill equation successfully modeled the experimental drying kinetics. The time factor $\tau$ in the Hill equation nicely explained two drying phases in the films. Solid-state phase changes occurring in the films during dehydration had a bearing on the drying kinetics and mechanisms. TGA can be used as a simple tool to determine the end points in drying processes using ovens or tunnels. The three-parameter Hill equation explained the drying kinetics and diffusion mechanisms of the solvent through the polymer films for the first time. This study advances our understanding of film drying, in particular for pharmaceutically relevant thin films.
\end{abstract}

KEY WORDS: PVA; HPMC; oral films; drying; physical properties; Hill equation.

\section{INTRODUCTION}

Polymeric films have many interesting applications in a number of industries, including pharmaceutical, food, cosmetics, and biomedical. In the field of pharmaceutics and drug formulation, polymer film technology has been explored as an alternative to existing solid dosage forms for effective delivery of drugs and improved patient compliance. Recently, polymeric oral (sublingual) films with fast/ultrafast drugrelease characteristics have emerged as an interesting option for a rapid therapeutic response. These films are also considered to be a good alternative for children and patients who have difficulty in swallowing conventional dosage forms like tablets and capsules. The clinical and manufacturing

Sitaram P. Velaga and Dariush Nikjoo contributed equally to this work.

Electronic supplementary material The online version of this article (doi:10.1208/s12249-017-0836-8) contains supplementary material, which is available to authorized users.

\footnotetext{
${ }^{1}$ Pharmaceutical and biomaterials research, Department of Health Sciences, Luleå University of Technology, SE-97187, Luleå, Sweden.

${ }^{2}$ To whom correspondence should be addressed. (e-mail: sitaram.velaga@ltu.se)
}

advantages of polymer oral films have recently been reviewed by Hoffmann et al. (1). Oral films are in general multicomponent systems comprising water-soluble polymers like HPMC, PVA, pullulan, and other functional excipients (solubilizers, plasticizers, flavors, etc.). For example, HPMC, PVA, and maltodextrin are among common polymers used in the marketed orodispersible films of ondansetron (Zuplenz®), risperidone (Risperidon HEXAL), and phenylephrine (Sudafed ${ }^{\circledR}$ PE) (1).

Solvent casting is one of the commonly employed industrially viable methods of manufacturing polymer films $(2,3)$. In this method, the film-forming polymer, functional excipients, and drug are mixed in water or water/organic solvent mixtures, and the resulting gel is cast onto polyethylene sheets using a knife coater. The wet film is then dried to remove the water/solvents. Spin coating is another popular solution-based film-forming method used in the biomedical and electronic industries (4). This method relies on the rapid spinning of the polymer solution using centrifugal force; this pushes the polymer solution out radially to form ultrathin films that are subsequently dried.

Drying is a critical process step that not only determines the residual water/solvent content of the thin films but also affects the film properties (2). Drying ovens (or tunnels) using convective drying processes are widely used in the oral film 
manufacturing $(1,5)$. In these methods, hot air is passed over or through the wet film; the drying rate is dependent on the heat transfer, solvent diffusion, and mass transfer coefficients. When manufacturing oral films, the drying process is designed to optimize the film thickness, mechanical properties, internal structure, and residual solvent/water content while minimizing the "ripple effect" (production of an uneven film) (6). The detrimental effects of temperature and drying time on the physicochemical stability of the drug and formulation excipients also need to be considered in the design of the filmdrying process. In general, the temperature and end point of the drying process are determined from trial and error experiments, which have poor efficiency and predictability (5). It is thus important to develop simpler, more materialsparing methods of predicting the drying kinetics of cast films during manufacturing.

The rate of drying can influence the crystal structure or solid state of the polymer (7). The nature of the polymer and any solid-state changes occurring during drying can affect the mass transfer rates, and thereby the drying process. For instance, an increase in the crystallinity of the polymer during the drying process slows the drying kinetics. Glassy skins can also form at drying temperatures below the glass transition temperature $\left(T_{\mathrm{g}}\right)$ of the polymer, which can trap solvent/ water in the drying film and influence the drying kinetics (8). The formation of intramolecular or intermolecular hydrogen bonds in or between the solvent/water molecules with polymer scaffolds can also affect the drying kinetics. Thus, understanding the relationships between the mass transfer phenomena (drying rate) and physical changes in the polymer is very important for tailoring the physico-mechanical properties of the oral film product $(9,10)$.

Theoretical, semi-empirical, and empirical models of the industrial drying process are widely used for nonpharmaceutical materials and films $(11,12)$. The drying mechanisms of semicrystalline polymers like PVA have been mathematically modeled in a few studies (13-17). These studies show that increasing the drying temperature and decreasing the molecular weight of the polymer can increase the rate of crystallization and the final crystallinity of the polymer. Lauritzen et al. have introduced a crystallization kinetics model (18) explaining the chain-folding rate and the crystallinity of the polymer during solvent movement (13-15). The crystallization rate was inversely related to the molecular weight, which is explained by the inability of long polymer chains to fold themselves into crystals. Wong et al. expanded on this theory, using the Flory-Huggins thermodynamic and Vrentas-Duda free-volume theories to form a consolidated crystallization kinetics and multi-solvent diffusion scheme $(16,17)$. This model is used to study the effects of external factors like temperature, film folding, diffusion, and evaporation of different solvents (1921). The drying process of the polymer matrices involves mass/ heat transfer; several models have been proposed to clarify the evolution of mass/heat transfer and the crystallinity of the matrices (22-24). However, all these models are focused on a single polymer rather than multicomponent polymeric films. The models are also very complicated and contain several parameters (such as saturated vapor pressure at the surface, the activity of the solvent, and the mass transfer coefficient) that can only be measured by intricate experiment. In fact, these models heavily rely on a number of assumptions and are difficult to use when modeling the drying process of films with low amounts of residual water. Therefore, there is a need for the development of simple models to explain the drying process of films.

The objective of this work was to provide new insights into film drying behavior and the effects on physical form changes in two water-soluble polymers: HPMC (amorphous) and PVA (semicrystalline), the most commonly used polymers in the formulation of oral films for drug delivery. Towards this objective, isothermal drying kinetics at different temperatures was studied. The well-known Hill equation with three parameters was proposed to explain drying behavior and mechanisms for the first time, as a simple alternative to complex traditional drying models. The relationship between the drying rate and the crystallinity of HPMC and PVA films was investigated. Isothermal dehydration behavior of films in thermo-gravimetric analysis (TGA) method was compared with that using the hot air oven to investigate whether TGA can be used as a simple tool for identifying the drying end points. These issues are of great importance not only to the pharmaceutical sciences, but also to food and other material sciences.

\section{THEORETICAL BACKGROUND}

The well-known Hill model, first presented by Hill (25), is a three-parameter equation that introduces a nonlinear relationship between two variables $(x, y)$; it is defined as follows:

$y=\frac{y_{\max } x^{n}}{c^{n}+x^{n}}$

where $y_{\max }, c$, and $n$ (the Hill coefficients) are the three parameters of the equation. The Hill model has been used extensively when the relationship between $x$ and $y$ is nonlinear where $y$ reaches constant values over time (26). It has also been widely used in pharmacology and the biosciences to study pharmacokinetic-pharmacodynamic relationships such as drugreceptor and dose-response interactions $(27,28)$. The descriptive and deterministic characteristics of the equation provide flexibility and effectiveness, which is why it has been so successfully implemented in different fields. The descriptive properties refer to experimental or clinical data while the deterministic aspects relate to physicochemical properties such as the mechanism of the reaction (26).

The probabilistic term $\frac{x^{n}}{c^{n}+x^{n}}$, as a cumulative distribution function $F(x)$ with random values for $x$, provides an indication of the descriptive aspects of the Hill equation and its special mathematical and graphical properties $(26,29)$. The first derivative of $F(x)$ as the probability density function $f(x)$ is explained by the following expression:

$f(x)=F^{\prime}(x)=\frac{n c^{n} x^{n-1}}{\left(c^{n}+x^{n}\right)^{2}}$

For $F(x)=P\{X \leq x\}=\frac{x^{n}}{c^{n}+x^{n}}, x \in R^{+}, c>0, n>0, F(x)$ includes biparametric probability functions in the positive numbers, where $n$ and $c$ are shape and size parameters that control the shape and size, respectively, of the graphs. 
It is clear that the transfer of heat and mass are implicated in the drying of polymers. Heat transfer involves thermal diffusion at both the air-film and contact-film interfaces. In contrast, mass transfer involves solvent diffusion only at the air-film interface. However, studies have shown that the effect of thermal diffusion on film drying kinetics can be neglected because it is so high $\left(\cong 10^{-7} \mathrm{~m}^{2} \mathrm{~s}^{-1}\right)$. Also, thermal diffusion is one thousand times faster than the maximum value of the mass diffusion coefficient. Hence, the focus of our study is the slower process: mass transfer (10).

Zhang et al. (9) have previously used a type of hyperbolic function to model mass transfer in the dehydration process; this is equivalent to the Hill equation with a fixed value for the shape parameter $(n=1$, i.e., simplified into two parameters). However, the twoparameter equation as used by Zhang et al. may not provide an accurate estimation of all types of experimental drying data (e.g., sigmoidal and hyperbolic). Hence, it becomes necessary to use the Hill equation "as is," with higher order coefficients and $n$ as a free parameter. In this study, the Hill equation was used in its full form to study the drying behavior of the polymer films. The weight loss, $W_{\text {loss }}$, (mass change) was defined as follows:

$W_{\text {loss }}=\frac{W_{\max } t^{n}}{\tau^{n}+t^{n}}$

$W_{\max }$ is the maximum weight of film lost during the duration of the dehydration process $(t), \tau$ is the time taken to reach the halfway point of weight loss (reflected in the size of the graph), and $n$ is the Hill coefficient (reflected in the shape of the graph). $W_{\text {loss }}$ (mass change) affects the distribution function $F(x)$ and the first derivative $K_{\mathrm{d}}$ (rate of drying) density function $f(x)$. Figure 1 shows illustrative plots of $F(x)$ and $K_{\mathrm{d}}$ that clearly indicate that the values of $\tau$ and $n$ change the size and shape of the graph. For example, the distribution function $F(x)$ takes a sigmoidal shape when $1>n>0$ and $n>1$ but is hyperbolic when $n=1$, and the plots increase in size $\left(W_{\max }\right)$ with increases in the value of $\tau$ (Fig. 1).
To calculate the drying rate $\left(K_{\mathrm{d}}\right)$ at any time, the first order differential of $W_{\text {loss }}$ can be solved as follows:

$K_{\mathrm{d}}=\left(\frac{d W_{\text {loss }}}{d t}\right)_{T}=\frac{n W_{\max } \tau^{n} t^{n-1}}{\left(\tau^{n}+t^{n}\right)^{2}}$

Understanding the physical meaning of the parameters in the Hill equation helps to clarify the dehydration process. An analysis of the physical parameters (Fig. 1) is presented below:

1. When $t \rightarrow \infty$ and $W_{\text {loss }}=W_{\max }, W_{\max }$ is the maximum weight loss fraction at the end of the drying experiment.

2. When $t=\tau$ and $W_{\text {loss }}=W_{\max } / 2, \tau$ is the time taken for $W_{\text {loss }}$ to reach half of $W_{\text {max }}$. As shown in the figure, the vertical line $\mathrm{MN}$ crosses the curve at point $\mathrm{Q}$ where the $\tau$ value approaches $W_{\max } / 2$.

3. When $t \rightarrow 0, W_{\text {loss }}=\frac{W_{\max } t^{n}}{\tau^{n}}$ becomes nonlinear and corresponds to the initial point of the drying process. It is important to notice that this equation clearly shows that $n$ (the shape parameter) can easily predict the initial part of the curve. In the special case where $n=1$, the equation changes to the linear equation $W_{\text {loss }}=\frac{W_{\max } t}{\tau}$ where $W_{\max } / \tau$ is the slope of line OM and $\mathrm{M}$ is the coordinate of $W_{\max }$ and $\tau$.

As can be concluded from the physical analysis of the parameters, $W_{\max }$ is the upper limit of the weight loss, which can be easily determined by the model. Furthermore, $n$ gives valuable information regarding the initial part of the dehydration curve, while $\tau$ is an important parameter that provides valuable insights into the mechanism of the drying process.

\section{MATERIALS AND METHODS}

\section{Materials}

HPMC (MW = 35,600) (Pharmacoat 606, Shin Etsu, Japan) and PVA $\left(\mathrm{MW}=23.4-25.1 \times 10^{4}\right)$ (Nippon Gohsei, Germany) were used to form the films. Glycerol anhydrous (Fluka, Sweden) was used as a plasticizer. Other excipients included starch (Maize
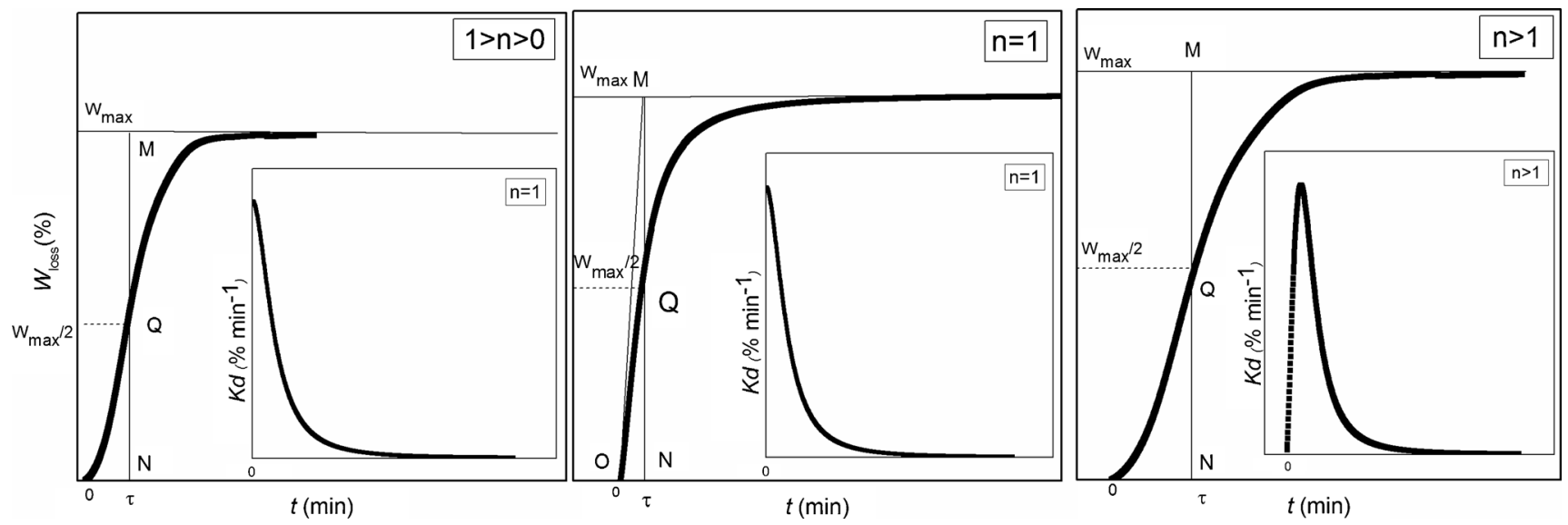

Fig. 1. Illustrative plots of percentage weight loss $\left(W_{\text {loss }} \%\right)$ from polymer films during the drying process, and the rate of drying $\left(K_{\mathrm{d}}\right)$ versus time, along with analysis of parameters. $W_{\max }=$ maximum weight loss; $\tau=$ time at which $W_{\text {loss }}=W_{\max } / 2$ 

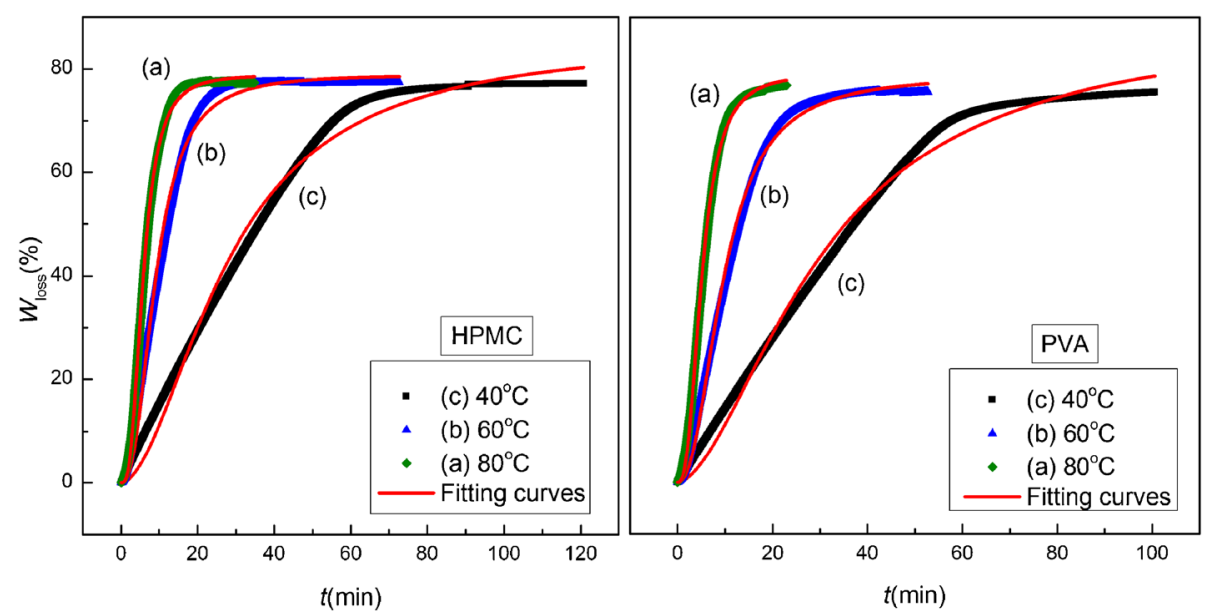

Fig. 2. Percentage weight loss $\left(W_{\text {loss }} \%\right)$ versus time for HPMC and PVA films during the drying process at various temperatures in an isothermal TGA apparatus

starch, Cargill, UK), Tween 80 (Sigma-Aldrich, Sweden), stevia (stevia ra98, Dominos Food Inc., USA), orange flavor (Kerry, USA), and blue color (Neelikon colors, India). De-ionized water (MilliQ, Millipore Sweden) and ethanol (Finsprit 95\%, Kemetyl, Sweden) were used without additional processing.

\section{Methods}

\section{Preparation of Thin Polymer Films}

HPMC films: Pre-cast solutions were prepared by adding HPMC $(14 \% w / w)$ to water $(78 \% w / w)$. Propylene glycol $(1.5 \%$ $w / w)$, plasticizers $(1.5 \% w / w)$, surfactant $(2 \% w / w)$, sweetener $(2 \% w / w)$, flavor, and color (ca $1 \% w / w)$ were added to this solution and the solution was magnetically stirred (IKA, Sweden) at $500 \mathrm{rpm}$ for $2 \mathrm{~h}$ at $22-24^{\circ} \mathrm{C}$.

PVA films: PVA $(11 \% w / w)$ was added to water/ethanol (68\% $w / w$ water and $10 \% w / w$ ethanol) solution. Subsequently, starch $(4 \% w / w)$, plasticizers $(2 \% w / w)$, surfactant $(2 \% w / w)$, sweetener $(2 \% \mathrm{w} / \mathrm{w})$, flavor, and color $(\mathrm{ca} 1 \% \mathrm{w} / \mathrm{w})$ were added to the polymer solution and the solution was magnetically stirred (IKA, Sweden) at $500 \mathrm{rpm}$ for $2 \mathrm{~h}$ at $22-24^{\circ} \mathrm{C}$.

The films were cast with a film applicator (Erichsen, Sweden) at a wet thickness of ca $650 \mu \mathrm{m}$ on a backing layer (Scotchpak, 3M Drug Delivery Systems) and dried as outlined in the next section. The casting rate was $5 \mathrm{~mm} / \mathrm{s}$.

\section{Kinetic Drying Studies}

TGA Method. TGA was carried out using a Q5000 TGA instrument (TA instruments, USA). The accurately weighed polymer gel $(25 \pm 0.01 \mathrm{mg}$; as prepared in the "Preparation of Thin Polymer Films" section), which had approximately the similar thickness as the samples used in oven drying, was placed in the center of the platinum sample pan and heated isothermally at 40,60 , and $80^{\circ} \mathrm{C}$ for different durations in a nitrogen atmosphere $(50 \mathrm{ml} / \mathrm{min})$; weight loss was then determined over a period of time. The TGA apparatus was also used to dry films isothermally at different temperatures before DSC and microscopic analysis, as described in the following section. The TGA apparatus was previously calibrated for weight and temperatures following the manufacturer's guidelines. The results were analyzed using TA universal analysis software (version 4.5A).

Laboratory Convection Oven. A laboratory convection drying oven (UFE 500, Memmert, Germany) was used to study the drying kinetics of the polymer films. Rectangular HPMC and PVA multicomponent films $\left(4 \times 10 \mathrm{~cm}^{2}\right)$ were placed in the oven immediately after the casting process and heated isothermally at $40 \pm 0.5,60 \pm 0.5$, and $80 \pm 0.5^{\circ} \mathrm{C}$ with an air flow rate of $0.5 \pm 0.02 \mathrm{~m} / \mathrm{s}$. The humidity was $<5 \%$. The weight loss at various time points was measured using a sensitive balance (AT261 Delta range, Mettler, Switzerland).

\section{Polarized Light Microscopy}

The HPMC and PVA films were examined (after drying for 10,30 , and $60 \mathrm{~min}$ at $80^{\circ} \mathrm{C}$ in TGA pans) using a polarized light microscope (DM 2500P, Leica, Germany) to investigate their structural features and crystallization.

Table I.. Summary of the Parameters for Thin Hydroxypropyl Methylcellulose (HPMC) and Polyvinyl Alcohol (PVA) Films Dried at Various Temperatures in an Isothermal Thermo-gravimetric Analysis Apparatus

\begin{tabular}{lrrrrrr}
\hline Sample temperature & $W_{\max }{ }^{a}$ & \multicolumn{1}{c}{$\tau^{a}$} & $n^{a}$ & $W_{\max } / \tau$ & $N^{b}$ & $R^{2 c}$ \\
\hline HPMC & & & & & & \\
$40^{\circ} \mathrm{C}$ & 85.62 & 27.92 & 1.84 & 3.06 & 2416 & 0.9893 \\
$60^{\circ} \mathrm{C}$ & 78.93 & 8.07 & 2.51 & 9.78 & 2183 & 0.9931 \\
$80^{\circ} \mathrm{C}$ & 78.91 & 5.81 & 2.90 & 13.58 & 2089 & 0.9980 \\
$\mathrm{PVA}$ & & & & & & \\
$40^{\circ} \mathrm{C}$ & 88.71 & 30.57 & 1.72 & 2.90 & 1509 & 0.9915 \\
$60^{\circ} \mathrm{C}$ & 78.73 & 9.66 & 2.28 & 8.15 & 1583 & 0.9962 \\
$80^{\circ} \mathrm{C}$ & 79.21 & 5.09 & 2.66 & 15.56 & 1374 & 0.9979 \\
\hline
\end{tabular}

${ }^{a}$ Parameters of the model (Eq. 3)

${ }^{b}$ Number of data point

${ }^{c}$ Reduced the chi-squared value of fitting 


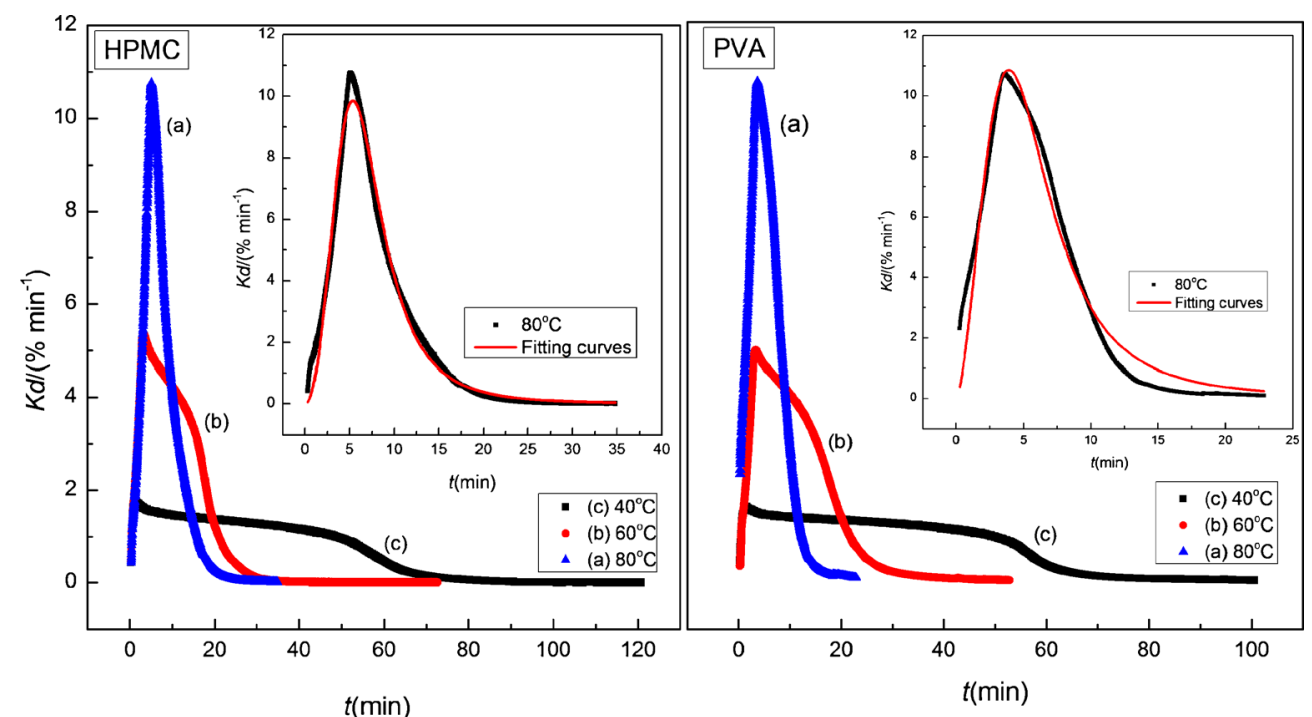

Fig. 3. Drying rates $\left(K_{\mathrm{d}}\right)$ of HPMC and PVA films at various temperatures in an isothermal TGA apparatus

The microscopy images were analyzed using image analysis software (Q Capture Pro 6.0).

\section{Hot-Stage Microscopy}

Hot-stage microscopy analysis was conducted using a hot stage (TMS 94, Linkam, UK) connected to a Lecia DM 2500P optical light microscope equipped with long working distance objectives. The gel (2-5 mg) was placed on the sample stage and kept isothermally at $80^{\circ} \mathrm{C}$ for $60 \mathrm{~min}\left(80^{\circ} \mathrm{C}\right.$ was chosen because crystallization could be monitored well at this temperature). The crystallization behavior was examined under cross polarizers.

\section{Scanning Electron Microscopy}

After the HPMC and PVA films were dried for 10, 30, and $60 \mathrm{~min}$ at $80^{\circ} \mathrm{C}$ in TGA pans, surface morphology analysis was carried out by SEM (JEOL JSM 6064LV, USA).

\section{Differential Scanning Calorimetry}

Differential scanning calorimetry (DSC) (DSC Q1000, TA instruments, USA) was used to study the solid-state transformations and crystallinity of the isothermally dried polymer films. After isothermal drying in TGA pans for 5, 10, 20,30 , and $60 \mathrm{~min}$ at $80^{\circ} \mathrm{C}, 2-5 \mathrm{mg}$ of the films were placed in aluminum pans and sealed non-hermetically. The samples were heated to $250^{\circ} \mathrm{C}$ at a constant heating rate of $10^{\circ} \mathrm{C} / \mathrm{min}$.

The same weight of raw HPMC and PVA powders was also placed in aluminum pans and sealed non-hermetically. Heatcool-heat experiments were then carried out to remove the thermal history of the samples. They were heated to $220-250^{\circ} \mathrm{C}$, cooled to $-50^{\circ} \mathrm{C}$, and heated to $220-250^{\circ} \mathrm{C}$ at $10^{\circ} \mathrm{C} / \mathrm{min}$.

\section{RESULTS AND DISCUSSION}

\section{Modeling the Drying Mechanisms of Polymer Films}

The dehydration process in water-soluble polymer films can be divided into three phases: rising temperature, constant
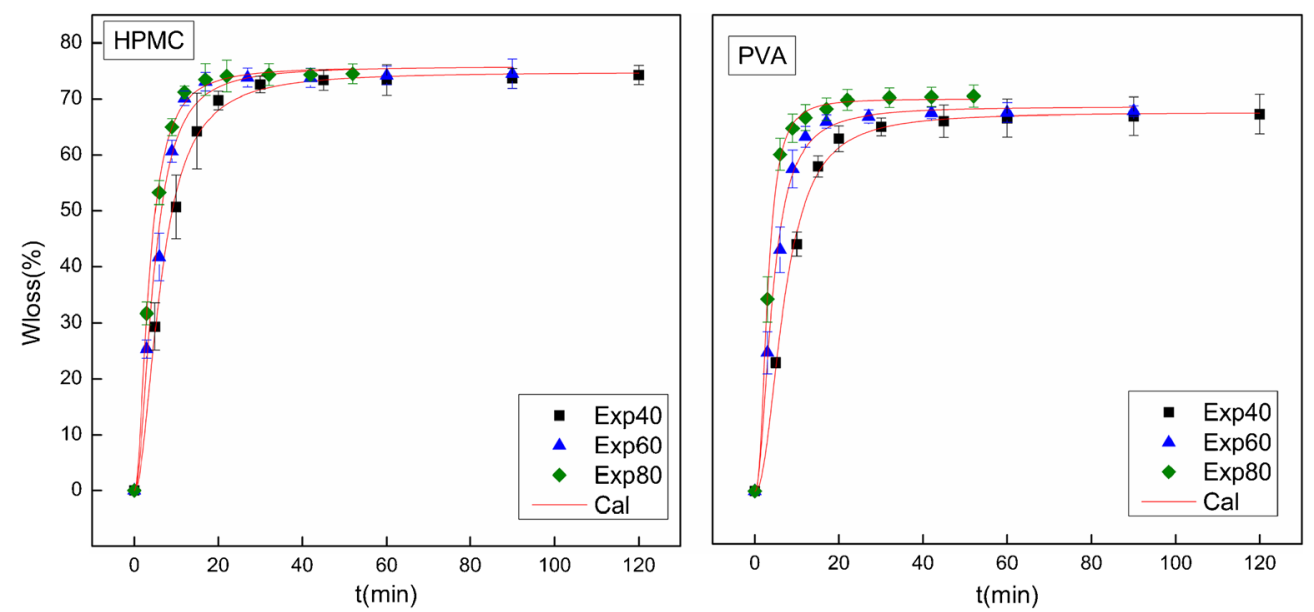

Fig. 4. Percentage weight loss $\left(W_{\text {loss }} \%\right)$ versus time for HPMC and PVA films during drying at various temperatures in a gravimetric convection oven 
Table II.. Summary of the Parameters for Hydroxypropyl Methylcellulose (HPMC) and Polyvinyl Alcohol (PVA) Films Dried at Various Temperatures in a Convection Oven

\begin{tabular}{lcccccc}
\hline Sample temperature & $W_{\max }{ }^{a}$ & $\tau^{a}$ & $n^{a}$ & $W_{\max } / \tau$ & $N^{b}$ & $R^{2 c}$ \\
\hline HPMC & & & & & & \\
$40^{\circ} \mathrm{C}$ & 74.80 & 6.39 & 2.01 & 11.70 & 10 & 0.9969 \\
$60^{\circ} \mathrm{C}$ & 75.83 & 4.65 & 2.02 & 16.30 & 10 & 0.9853 \\
$80^{\circ} \mathrm{C}$ & 75.76 & 3.62 & 1.97 & 20.92 & 10 & 0.9973 \\
$\mathrm{PVA}$ & & & & & & \\
$40^{\circ} \mathrm{C}$ & 71.61 & 6.98 & 2.16 & 10.25 & 10 & 0.9972 \\
$60^{\circ} \mathrm{C}$ & 72.72 & 4.18 & 2.01 & 17.39 & 10 & 0.9946 \\
$80^{\circ} \mathrm{C}$ & 74.16 & 3.03 & 2.46 & 24.47 & 10 & 0.9988 \\
\hline
\end{tabular}

${ }^{a}$ Parameters of the model (Eq. 3)

${ }^{b}$ Number of data point

${ }^{c}$ Reduced the chi-squared value of fitting

temperature, and diffusion (5). In the first phase (rising temperature), the temperature increases linearly on the surface of the film and, using a heat transfer process, the polymer film is heated rather than dried. In contrast, the second and third phases involve mass transfer processes, which is dominant in the drying process of water-soluble polymers.

Previously, the mass transfer processes were evaluated to predict the structure and final performance of the films, and authors thought of drying as a two-phase process (911). The constant temperature phase is associated with the evaporation of the solvent from the surface and external layers of the film (i.e., fast mass transfer), which creates a flux from the core to the solid-air interface. In this fast phase, the activity of the solvent is near 1 and the vapor pressure from evaporation can be assumed to be equal to that of the pure solvent. In the diffusion phase, the concentration of the solvent declines in the external layer, resulting in a slower evaporation rate driving the diffusion of the solvent from the core to the external layer (i.e., slow mass transfer). This slow mass transfer phase is significantly affected by the physicochemical properties of the polymer films. In recent years, the weight or volume fraction of the solvent and the mass ratio of residual solvent to initial solvent have been used to model the mass transfer process $(10,13,16,17)$. These mass transfer processes and $W_{\text {loss, }}$, which is related to the mass change and provides a simple explanation of the mass transfer processes, are the focus of this study.

\section{Modeling the Dehydration Process in a TGA Apparatus}

Figure 2 shows the experimental percentage $W_{\text {loss }}$ as a function of time and the model curves for the HPMC and PVA films at various temperatures. The results for $W_{\max }, \tau, n$, and the regression coefficient $\left(R^{2}\right)$ are given in Table I. As shown in Fig. 2 and Table I, Eq. 3 fitted the experimental data well, although the curve fit was slightly better at $80^{\circ} \mathrm{C}$ $\left(R^{2} \geq 0.9979\right)$ than at other temperatures for both polymers. Thus, the proposed model (Eq. 3) based on the Hill equation successfully modeled the drying process for the tested polymer films.

The drying rates for the HPMC and PVA films are shown in Fig. 3. Again, Eq. 4 was successful in fitting the experimental data for both films at all temperatures, although the model fit was best at $80^{\circ} \mathrm{C}$ (Fig. 3). Figure 3 also shows that the fit was better for HPMC than for PVA, which might be because of the amorphous nature of HPMC. The steep and shallow regions of the $K_{\mathrm{d}}$ curves can be attributed to faster and slower kinetics of mass transfer (drying), as explained above. Zhang et al. and Guerrier et al. made similar observations of a two-step process while PVA, methyl ethyl ketone, and polybutyl methacrylate polymer films were drying $(9,10)$.

\section{Modeling the Drying Process in a Convection Oven}

As motivated, it was of interest to relate drying kinetics of casted films in a convective oven with TGA. For this purpose, larger films $\left(4 \times 10 \mathrm{~cm}^{2}\right)$ were cast for monitoring the dehydration process in a convection oven. Figure 4 presents the experimental percentage $W_{\text {loss }}$ versus time and
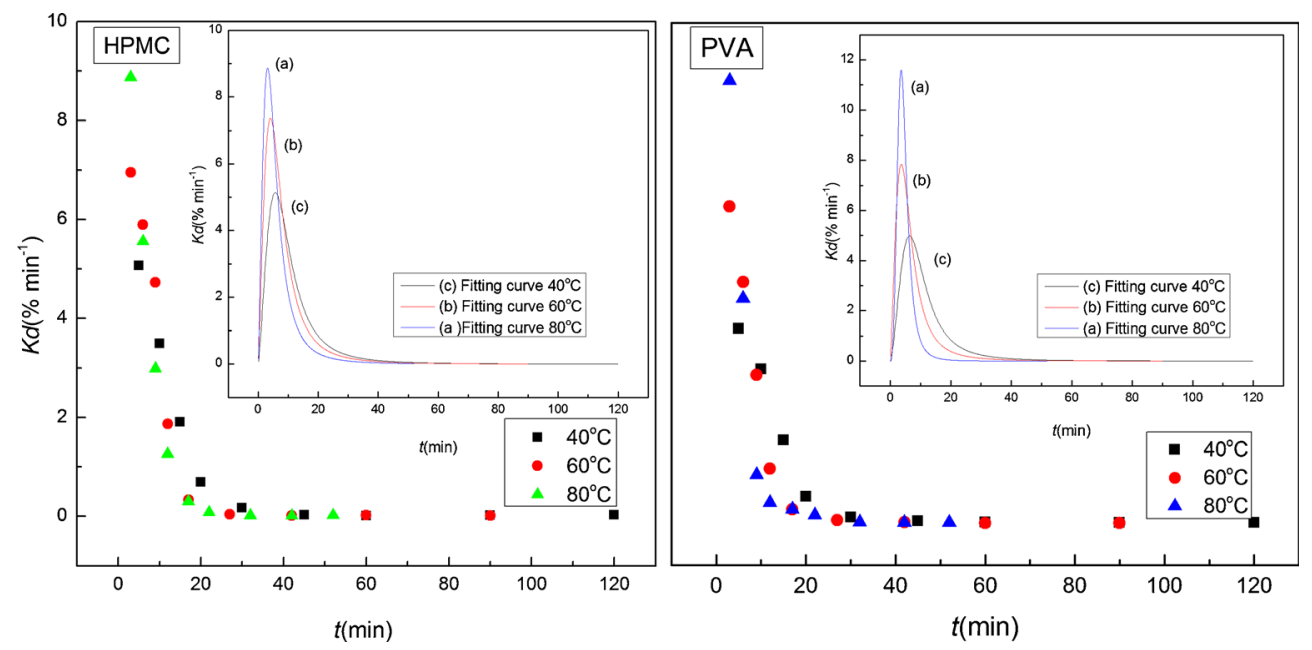

Fig. 5. Drying rates $\left(K_{\mathrm{d}}\right)$ of HPMC and PVA films at different temperatures in a gravimetric convection oven 

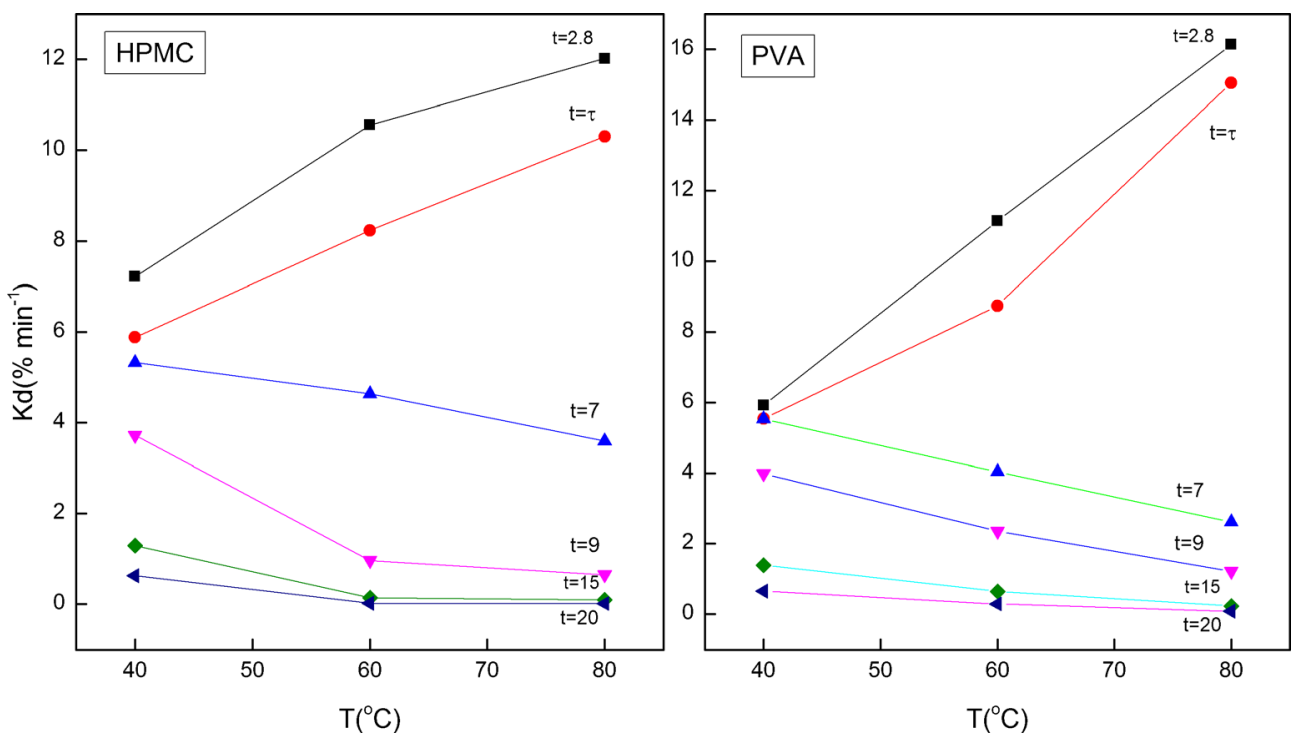

Fig. 6. Drying rates $\left(K_{\mathrm{d}}\right)$ of HPMC and PVA films before and after the characteristic time $(\tau)$ at various temperatures

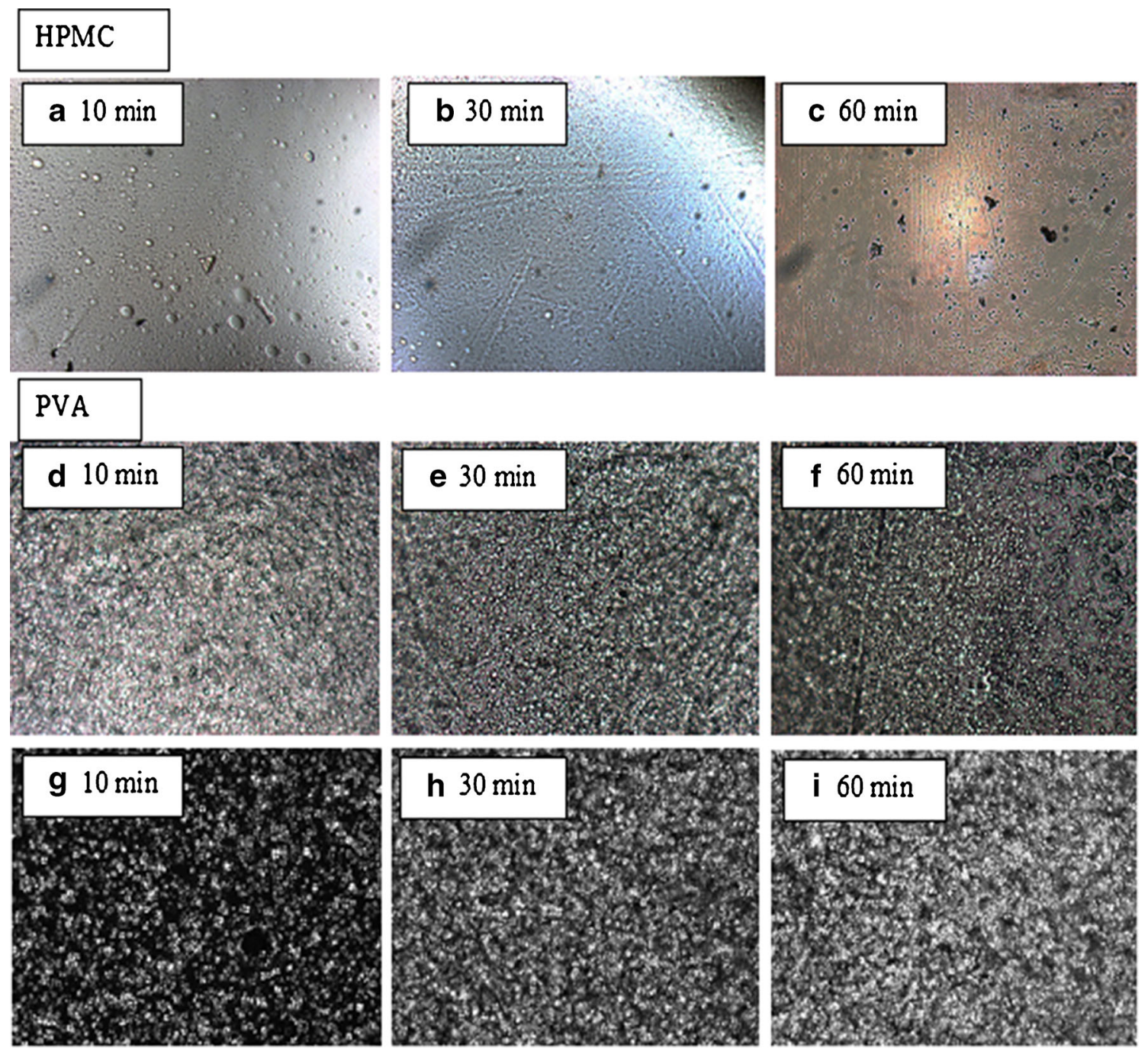

Fig. 7. a-c Optical microscopy pictures of post dried films of HPMC and $\mathbf{d}-\mathbf{f}$ the optical and $\mathbf{g}-\mathbf{i}$ polarized microscopy pictures of post dried films of PVA after drying in the thermo-gravimetric analysis apparatus at $80^{\circ} \mathrm{C}$ for different time periods (under $\times 10$ magnification) 

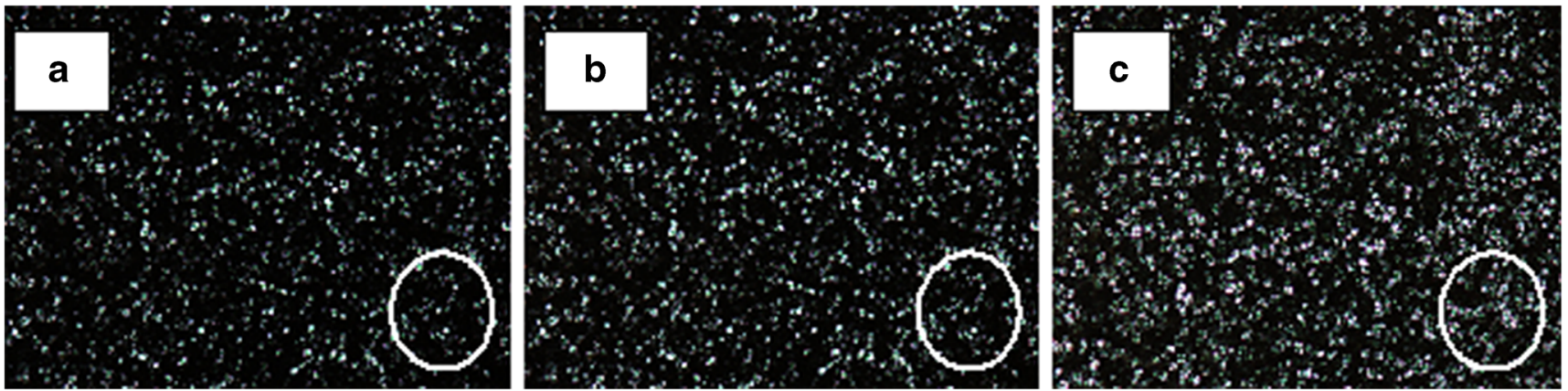

Fig. 8. Hot-stage microscopy images of PVA at $80^{\circ} \mathrm{C}$ under $\times 10$ magnification using crossed polarizers (images after a $10 \mathrm{~min}$, b $30 \mathrm{~min}$, c 60 min drying)

the model curves for HPMC and PVA films at various temperatures. The fitting parameters for Eq. 3 and the corresponding $R^{2}$ values are presented in Table II for these larger films. On the basis of the $R^{2}$ values, it can be concluded that Eq. 3 successfully simulated the experimental data at different temperatures for both polymers.

As discussed above, Eq. 3 is a simple model with only three parameters. There is an upper limit to the loss of weight at each temperature $\left(W_{\max }\right)$ and this can be easily determined by the model. Thus, prolonging the drying time over a certain point may not be beneficial. Moreover, the drying rate $K_{\mathrm{d}}$, which is the differential form of $W_{\text {loss }}$, can also be easily calculated by Eq. 4 for larger films in the convection oven. Figure 5 shows the drying rate for HPMC and PVA films at different temperatures. Interestingly, although experimental data for the initial drying process in the oven were not available (because of delays in transferring the films to the oven), the model predicted all the stages of the drying process for the HPMC and PVA films (Fig. 5). In contrast, the model proposed by Zhang et al. (9) with only two parameters (and a constant shape parameter) did not explain the initial stage of the drying process. Furthermore, irrespective of the size of the films, two distinct phases of the drying process were observed (Figs. 3 and 5). This suggests, as expected, that our proposed model works independently of the size of the films when modeling the drying kinetics. Moreover, the drying curves of the HPMC and PVA films were comparable in the TGA apparatus and the convection oven at higher temperatures (i.e., $80^{\circ} \mathrm{C}$ ).

\section{Drying Rate $\left(K_{d}\right)$ and Drying Time}

Figure 6 shows plots of the dehydration rates and drying times (including the specific time $\tau$ ) at different temperatures. The specific time $\tau$ is the time during drying determined by the model to be the point at which the weight loss is equal to $W_{\max } / 2$ (Fig. 1). The drying rate at $t=\tau$ can be easily calculated using Eq. 4 . This important point is the point at which half of the solvent has been removed from the polymer films.

As can be seen from Fig. 6, $K_{\mathrm{d}}$ was the highest at the beginning of the drying process for all the studied temperatures for both HPMC and PVA. Before the characteristic time $\tau, K_{\mathrm{d}}$ increased with increasing temperature but, after $\tau, K_{\mathrm{d}}$ decreased with increasing temperature for a while and then leveled out (Fig. 6). This can be explained by the biphasic diffusion of the solvent; the initial drying rate follows Fickian diffusion rules and non-Fickian diffusion dominates the latter phase. The differences in diffusion mechanisms originate from changes in the polymer structure that occur during the drying process (30). In Fickian diffusion, the solvent flux depends on the concentration of the solvent in the film, which is higher at the beginning of the drying process. Fickian diffusion is dominant at temperatures above $T_{\mathrm{g}}$ where the polymer is in a rubbery state $(19,20)$. When the polymers are rubbery, the diffusion coefficient is sensitive to the temperature. As the drying continues, solvent levels in the polymer outer layers fall, leading to an increase in the $T_{\mathrm{g}}$ of the polymer. Consequently, the polymer enters the glassy region and non-Fickian diffusion dominates.

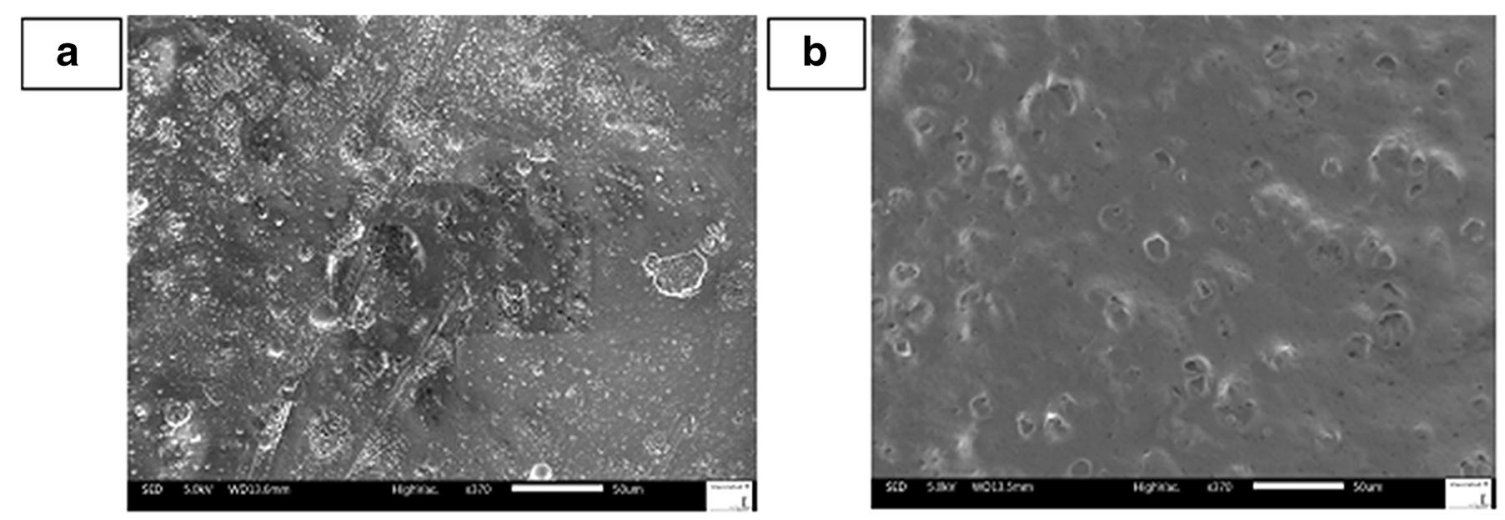

Fig. 9. Scanning electron microscopy micrographs of the post dried films of a HPMC and $\mathbf{b}$ PVA after drying at $80^{\circ} \mathrm{C}$ for $60 \mathrm{~min}$ 

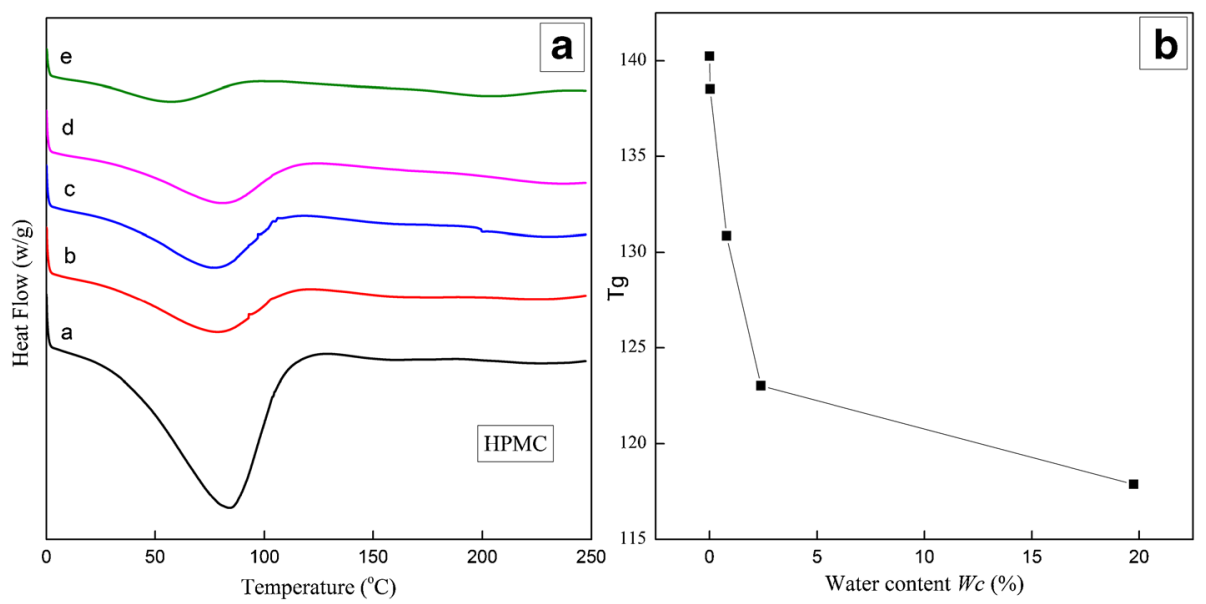

Fig. 10. a Differential scanning calorimetry thermograms of post dried HPMC films after drying in the TGA at $80^{\circ} \mathrm{C}$ for $a: 5 \mathrm{~min}, b: 10 \mathrm{~min}, c: 20 \mathrm{~min}, d: 30 \mathrm{~min}$, and $e: 60 \mathrm{~min}$. b The $T_{\mathrm{g}} \mathrm{s}$ of the HMPC films versus water content $W_{\mathrm{c}}$

The values of the $\tau$ and $n$ parameters for HPMC and PVA films are reported in Table I for the TGA apparatus and Table II for the convection oven. For the convection oven study, the HPMC $\tau$ was $6.39\left(6^{\prime}: 39^{\prime \prime}\right), 4.65\left(5^{\prime}: 05^{\prime \prime}\right)$, and $3.62 \min \left(4^{\prime}: 02^{\prime \prime}\right)$ at 40,60 , and $80^{\circ} \mathrm{C}$, respectively, and the PVA $\tau$ was $6.98\left(7^{\prime}: 38^{\prime \prime}\right), 4.18\left(4^{\prime}: 18^{\prime \prime}\right)$ and $3.03 \mathrm{~min}\left(3^{\prime}: 03^{\prime \prime}\right)$ at 40,60 , and $80^{\circ} \mathrm{C}$, respectively (Table II). This means that the Fickian diffusion, mainly originating from the outer layers of both films, was relatively short-lived before it turned to nonFickian diffusion after $t=\tau$. Moreover, $n>1$ values also describe the sigmoidal shape of the weight loss curve as presented in Fig. 1, suggesting that the drying process mechanisms for HPMC and PVA were similar. The drying parameters $(n$ and $\tau$ ) for HPMC and PVA films with TGA and oven drying were approaching similar values with increase in the temperature (for example $80^{\circ} \mathrm{C}$ ) (Tables I and II). This indicates the potential of TGA as a quick tool for determining drying end points and understanding the drying kinetics of films in larger unit operations (like drying

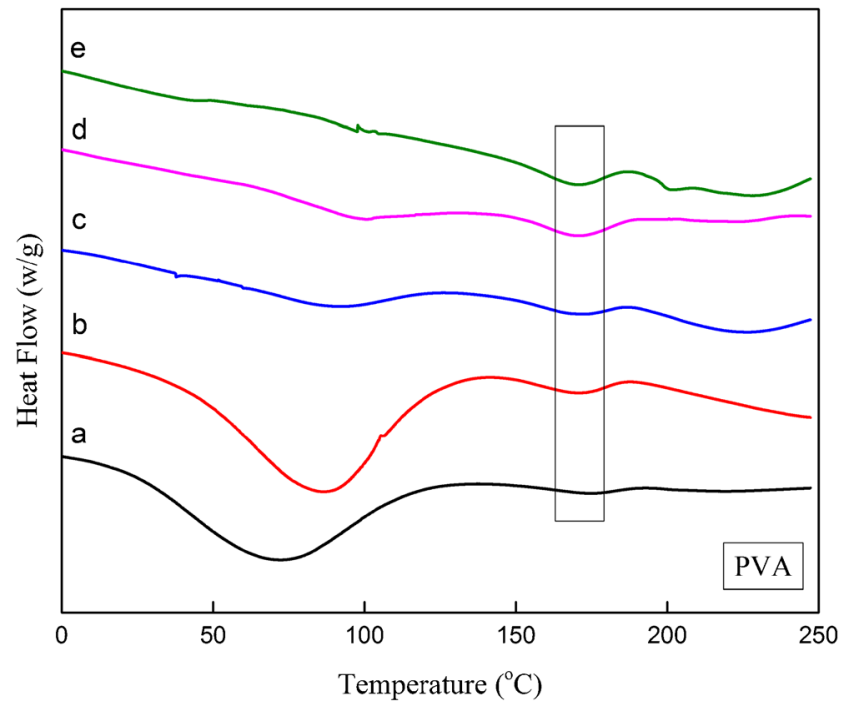

Fig. 11. Differential scanning calorimetry thermograms of post dried PVA films after drying in the TGA appratuse at $80^{\circ} \mathrm{C}$ for $a: 5 \mathrm{~min}, b$ : $10 \mathrm{~min}, c: 20 \mathrm{~min}, d: 30 \mathrm{~min}$, and $e: 60 \mathrm{~min}$ tunnels) at higher temperatures i.e., $\geq 80^{\circ} \mathrm{C}$.

$\mathrm{HPMC}$ is an amorphous polymer with $T_{\mathrm{g}} \cong 143.8^{\circ} \mathrm{C}$ (Fig $\mathrm{S} 1$ supplementary information), and the drying temperatures used in this study $\left(40,60\right.$, and $\left.80^{\circ} \mathrm{C}\right)$ were below this. Therefore, the diffusion of the solvent was Fickian for a very short period as the dehydration process was taking place in the glassy state. PVA is a semicrystalline polymer with $T_{\mathrm{g}} \cong 72.2^{\circ} \mathrm{C}$ (Fig S2 supplementary information), which may have hindered diffusion of the solvent/water molecules, leading to the deviation from the proposed model (Fig. 3). These results indicate that effective dehydration occurs in the rubbery state (Fickian diffusion) rather than in the glassy state (non-Fickian diffusion). Thus, the formation of a glassy skin, which usually happens when the drying temperature is below the $T_{\mathrm{g}}$, must be avoided. These results emphasize the importance of understanding the physical state of the polymer when designing the drying process for polymer films.

\section{Microscopy and Solid-State Characterization}

\section{Microscopic Examination}

After isothermal drying at different temperatures, the cast films were examined using optical and polarized microscopy; the results are shown in Fig. 7. The HMPC films (Fig. $7 \mathrm{a}-\mathrm{c})$ appeared smooth and the residual water in the microstructure was observed to decrease as the drying time increased at $80^{\circ} \mathrm{C}$. Moreover, no crystalline domains were observed for HPMC films under polarization microscopy (data not were shown). The PVA films appeared to be irregular (Fig. 7d-f) and the birefringence seen under cross polarizers suggested crystalline domains (Fig. $7 \mathrm{~g}-\mathrm{i}$ ). The size and density of these crystalline domains increased with increasing drying time from 10 to $60 \mathrm{~min}$ at $80^{\circ} \mathrm{C}$.

In situ crystallization of PVA was studied using hot-stage microscopy (HSM). As shown in Fig. 8, the size of the spherulites increased with drying time at $80^{\circ} \mathrm{C}$, indicating increasing crystallinity. These results are in line with the results of microscopic examination of the dried films (Fig. 7).

The microstructure of the HPMC and PVA films after drying at $80^{\circ} \mathrm{C}$ for $60 \mathrm{~min}$ is shown in Fig. 9. The surface of the PVA films was almost smooth and uniform, with small 
holes. In contrast, the HPMC films had an undulant surface and larger holes caused by water removal. This could be attributed to a higher water content in the HPMC films, which are known to have a stronger affinity for water molecules because of the presence of different hydrophilic and hydroxyl groups. In fact, the presence of more water was also evident from the DSC thermograms (see endotherm for water evaporation in Figs. 10 and 11).

\section{Thermal Behavior of the Polymer During Drying}

Figures 10a and 11 show DSC thermograms of HPMC and PVA films after drying at $80^{\circ} \mathrm{C}$ in the TGA apparatus for 5, 10, 20, 30, and $60 \mathrm{~min}$ (a-e). Only the highest drying temperature $\left(80^{\circ} \mathrm{C}\right)$ is presented, because the solid-state changes are more evident and the results are representative of trends at the other temperatures. The thermogram of pure (raw) HPMC showed an extended endothermic peak around $70^{\circ} \mathrm{C}$, which is attributed to the removal of water and a change in the heat capacity at $143.8^{\circ} \mathrm{C}$ corresponding to the $T_{\mathrm{g}}\left(T_{\mathrm{g}}(\mathrm{I})\right)$ of the polymer (Fig. $\mathrm{S} 1$ supplementary information). These results are in agreement with those reported in the literature (31-33). Endothermic peaks representing water evaporation appeared in approximately the same regions for the HPMC films, and eventually disappeared with increasing drying times (Fig. 10a (a-e)). The $T_{\mathrm{g}}$ for the dry HPMC films was $140^{\circ} \mathrm{C}$, i.e., lower than the $T_{\mathrm{g}}$ of pure HPMC, which may be explained by the plasticizing effects of glycerol (34). Moreover, the $T_{\mathrm{g}} \mathrm{s}$ of the HMPC films were decreased with increases in water content $\left(W_{\mathrm{c}}\right)$ because of the plasticizing effects of water in the microstructure (Fig. 10b) $(35,36)$. These changes in physical state and microstructure could affect the thermal and mechanical properties of the polymers. As discussed earlier, the highest drying temperature (i.e., $80^{\circ} \mathrm{C}$ ) employed in this study was lower than the $T_{\mathrm{g}}$ for these films, which promoted the formation of a glassy state during the degradation process.

The pure (raw) PVA thermogram showed a heat capacity change at $72.2^{\circ} \mathrm{C}\left(T_{\mathrm{g}}(\mathrm{I})\right)$, which is attributed to the $T_{\mathrm{g}}$ of PVA followed by an endothermic event at $188.6^{\circ} \mathrm{C}\left(T_{\text {onset }}\right)$, corresponding to the melting point of the polymer (Fig. S2, supplementary information). The DSC thermal behavior indicated that PVA is a semicrystalline polymer, which is in line with previous reports (37). In the DSC thermograms for PVA films, an endothermic peak corresponding to water evaporation near $70^{\circ} \mathrm{C}$ was followed by a melting endotherm at $174.5^{\circ} \mathrm{C}\left(T_{\text {onset }}\right)$. The $T_{\mathrm{g}}$ peak did not appear for the PVA films; it may have overlapped with the solvent (water/ethanol) evaporation peak. The DSC thermograms for the PVA films also indicated that the enthalpy of evaporation of the residual solvent decreased and the heat of fusion of the melting peaks increased as the drying time increased (Fig. 11(a-e)). Moreover, there was no change in the heat capacity around $72^{\circ} \mathrm{C}$ in the thermogram of dried PVA (Fig. 11(e)) confirming the absence of $T_{\mathrm{g}}$. This reflects the increase in the crystallinity (ca 23.3 to $42.8 \%$ ) of PVA films as the drying time increases. The crystal growth observed in the microscopy studies strongly supported these findings. As discussed earlier, these physical form changes during dehydration might alter the diffusion kinetics/mechanisms and might, therefore, affect the drying and structure of the final product.

\section{CONCLUSIONS}

Drying is an important operation in the manufacturing of oral films and the drying conditions affect the physicomechanical properties of the film and the stability of the drug. This study systematically investigated the drying behavior of two multicomponent oral films based on HPMC (amorphous) and PVA (semicrystalline). The Hill equation with three parameters was used to model the diffusion kinetics of water/solvent through the film during the drying process. The physical meaning of the model parameters was explained. The half-maximal time $(\tau)$ parameter in the Hill equation successfully explained two phases: Fickian and non-Fickian drying stages. It was found that effective dehydration occurred while the films were in a rubbery state and, thus, the drying conditions must be selected to prevent the formation of a glassy state in amorphous films. For semicrystalline polymers like PVA, the size and density of the crystalline domains increased with increasing drying times, and these solid-state changes also influenced the drying kinetics. This study has shown that the TGA method can be used as a simple tool in designing the drying process for thin films. The results of the study have provided fundamental insights into the drying processes of thin polymer films that are highly relevant for diverse industries such as pharmaceutical, food, and material sciences. Future work will focus on extending the applicability of the Hill model to other hydrophilic and hydrophobic polymers cast from aqueous and organic solvents, and also on investigating the effects of the thickness of the film in the development of new models.

\section{ACKNOWLEDGMENTS}

The authors wish to acknowledge Nippon Gohsei, Germany, for the generous supply of PVA.

Open Access This article is distributed under the terms of the Creative Commons Attribution 4.0 International License (http://creativecommons.org/licenses/by/4.0/), which permits unrestricted use, distribution, and reproduction in any medium, provided you give appropriate credit to the original author(s) and the source, provide a link to the Creative Commons license, and indicate if changes were made.

\section{REFERENCES}

1. Hoffmann EM, Breitenbach A, Breitkreutz J. Advances in orodispersible films for drug delivery. Expert Opin Drug Deliv. 2011;8:299-316.

2. Tsuji H, Ikada Y. Properties and morphologies of poly(1lactide): 1. Annealing condition effects on properties and morphologies of poly(1-lactide). Polymer. 1995;36:2709-16. doi:10.1016/0032-3861(95)93647-5.

3. Bhatla A, Yao YL. Effect of laser surface modification on the crystallinity of poly(L-lactic acid). J Manuf Sci Eng. 2009;131:051004.

4. Vuddanda PR, Mathew AP, Velaga S. Electrospun nanofiber mats for ultrafast release of ondansetron. React Funct Polym. 2016;99:65-72.

5. Abbott SJ, Kapur N, Sleigh PA, Thompson HM, Summers JL. Industrial Film Drying. Convertech \& e-Print, 1. ISSN 21856931. 2011. 
6. Susarla R, Sievens-Figueroa L, Bhakay A, Shen Y, Jerez-Rozo JI, Engen W, et al. Fast drying of biocompatible polymer films loaded with poorly water-soluble drug nano-particles via low temperature forced convection. Int J Pharm. 2013;455:93-103.

7. Hsu ST, Yao YL. Effect of film formation method and annealing on morphology and crystal structure of poly(L-lactic acid) films. J Manuf Sci Eng. 2014;136:021006.

8. Wong SS, Altinkaya SA, Mallapragada SK. Multi-zone drying schemes for lowering the residual solvent content during multicomponent drying of Semicrystalline polymers. Dry Technol. 2007;25:995.

9. Zhang H, Wang Q, Li L. Dehydration of water-plasticized poly(vinyl alcohol) systems: particular behavior of isothermal mass transfer. Polym Int. 2009;58:97-104.

10. Guerrier B, Bouchard C, Allain C, Bénard C. Drying kinetics of polymer films. AICHE J. 1998;44:791-8.

11. Kudra T, Mujumdar AS. Advanced drying technologies. Second Edition ed. USA: CRC Press, Taylor \& Francis Group; 2009.

12. Mujumdar AS, Law CL. Drying technology: trends and applications in postharvest processing. Food Bioproc Tech. 2010;3:843-52.

13. Ngui MO, Mallapragada SK. Understanding isothermal semicrystalline polymer drying: mathematical models and experimental characterization. J Polym Sci Polym Phys. 1998;36:2771-80.

14. Wong S, Altinkaya SA, Mallapragada SK. Crystallization of poly(vinyl alcohol) during solvent removal: infrared characterization and mathematical modeling. J Polym Sci Polym Phys. 2007;45:930-5.

15. Ngui MO, Mallapragada SK. Quantitative analysis of crystallization and skin formation during isothermal solvent removal from semicrystalline polymers. Polymer. 1999;40:5393-400.

16. Wong S, Altınkaya SA, Mallapragada SK. Drying of semicrystalline polymers: mathematical modeling and experimental characterization of poly(vinyl alcohol) films. Polymer. 2004;45:5151-61.

17. Wong S, Altinkaya SA, Mallapragada SK. Understanding the effect of skin formation on the removal of solvents from semicrystalline polymers. J Polym Sci Polym Phys. 2005;43:3191-204.

18. Lauritzen JI, Hoffman JD. Theory of formation of polymer crystals with folded chains in dilute solution. 1960; 64:73.

19. Vrentas JS, Duda JL. Diffusion in polymer—solvent systems. I. Reexamination of the free-volume theory. J Polym Sci Polym Phys Ed. 1977;15:403-16.

20. Vrentas JS, Duda JL. Diffusion in polymer-solvent systems. II. A predictive theory for the dependence of diffusion coefficients on temperature, concentration, and molecular weight. J Polym Sci Polym Phys Ed. 1977;15:417-39.

21. Favre E, Nguyen QT, Clement R, Neel J. Application of FloryHuggins theory to ternary polymer-solvents equilibria: a case study. Eur Polym J. 1996;32:303-9. doi:10.1016/00143057(95)00146-8.
22. Allanic N, Salagnac P, Glouannec P. Study of the drying behavior of poly(vinyl alcohol) aqueous solution. Macromol Symp. 2005;222:253-8.

23. Lamaison V, Scudeller Y, Bardon J, Danes F, Peng S, Dory J. Étude expérimentale des phénomènes de transfert lors du séchage et de la cuisson de films de peinture sous rayonnement infrarouge. Int J Therm Sci. 2001;40:181-94. doi:10.1016/S12900729(00)01207-2.

24. Navarri P, Andrieu J. High-intensity infrared drying study. Chem Eng Process. 1993;32:319-25. doi:10.1016/02552701(93)85016-9.

25. Hill AV. The possible effects of the aggregation of the molecules of haemoglobin on its dissociation curves. J Physiol Lond. 1910;40:i-vii.

26. Goutelle S, Maurin M, Rougier F, Barbaut X, Bourguignon L, Ducher M, et al. The Hill equation: a review of its capabilities in pharmacological modelling. Fundam Clin Pharmacol. 2008;22:633-48.

27. Mager DE, Wyska E, Jusko WJ. Diversity of mechanism-based pharmacodynamic models. Drug Metab Dispos. 2003;31:510-8.

28. Csajka C, Verotta D. Pharmacokinetic-pharmacodynamic modelling: history and perspectives. J Pharmacokinet Pharmacodyn. 2006;33:227.

29. Burr IW. Cumulative frequency functions. Ann Math Stat. 1942;13:215-32.

30. Doumenc F, Guerrier B. Estimating polymer/solvent diffusion coefficient by optimization procedure. AICHE J. 2001;47:98493.

31. McPhillips H, Craig DQM, Royall PG, Hill VL. Characterisation of the glass transition of HPMC using modulated temperature differential scanning calorimetry. Int J Pharm. 1999;180:83-90.

32. Joshi SC. Sol-gel behavior of Hydroxypropyl methylcellulose (HPMC) in ionic media including drug release. Materials. 2011:4:1861-905.

33. Ford JL. Thermal analysis of hydroxypropylmethylcellulose and methylcellulose: powders, gels and matrix tablets. Int J Pharm. 1999;179:209-28.

34. Chen P, Zhang L, Cao F. Effects of moisture on glass transition and microstructure of glycerol-plasticized soy protein. Macromol Biosci. 2005;5:872-80.

35. Heljo VP, Nordberg A, Tenho M, Virtanen T, Jouppila K, Salonen $\mathrm{J}$, et al. The effect of water plasticization on the molecular mobility and crystallization tendency of amorphous disaccharides. Pharm Res. 2012;29:2684-97.

36. Perfetti G, Alphazan T, Wildeboer WJ, Meesters GM. Thermophysical characterization of Pharmacoat ${ }^{\circledR}$ 603, Pharmacoat ${ }^{\circledR} 615$ and Mowiol ${ }^{\circledR}$ 4-98. J Therm Anal Calorim. 2012;109:203-15.

37. Pshezhetskii VS, Rakhnyanskaya AA, Gaponenko IM, Nalbandyan YE. A differential scanning calorimetry study of polyvinyl alcohol. PolymSci USSR. 1990;32:722-6. doi:10.1016/ 0032-3950(90)90394-L. 